\title{
Comparison of shock response spectrum for different gun tests
}

\author{
J.A. Cordes ${ }^{\mathrm{a}, *}$, P. Vo ${ }^{\mathrm{b}}$, J.R. Lee ${ }^{\mathrm{a}}$, D.W. Geissler ${ }^{\mathrm{a}}$, J.D. Metz ${ }^{\mathrm{a}}$, D.C. Troast ${ }^{\mathrm{a}}$ and A.L. Totten $^{\mathrm{a}}$ \\ ${ }^{a}$ U.S. Army ARDEC, Fuze and Precision Armaments Technology (RDAR-MEF-E), Picatinny Arsenal, NJ, USA \\ ${ }^{\mathrm{b}}$ Raytheon Missile Systems, Tucson, AZ, USA
}

Received 9 January 2012

Revised 26 October 2012

Accepted 20 November 2012

\begin{abstract}
The Soft Catch Gun at Picatinny Arsenal is regularly used for component testing. Most shots contain accelerometers which record accelerations as a function of time. Statistics of accelerometer data indicate that the muzzle exit accelerations are, on average, higher than tactical firings. For that reason, Soft Catch Gun tests with unusually high accelerations may not be scored for Lot Acceptance Tests (LAT) by some customers. The 95/50 Normal Tolerance Limit (NTL) is proposed as a means of determining which test results should be scored. This paper presents comparisons of Shock Response Spectra (SRS) used for the 95/50 scoring criteria. The paper also provides a Discussion Section outlining some concerns with scoring LAT results based on test results outside of the proposed 95/50 criteria.
\end{abstract}

Keywords: Shock response spectrum, accelerations, soft recovery vehicle, Soft Catch Gun, macs 5 charge, setback, set forward, balloting, normal tolerance limit, Excalibur

\section{Introduction}

Precision munitions, such as the Army's $155 \mathrm{~mm}$ Excalibur, include complex subsystems that undergo qualification and acceptance tests designed to emulate the high-g tactical environment. The purpose of these tests is to demonstrate function and reliability of production lots. When failures occur, they are investigated, root cause is determined and improvements are made. Most of these tests are instrumented with pressure gages, accelerometers or both [1-7]. Accelerometer data is reviewed for trends, used for failure reviews, and utilized in design and redesign of components [8-14]. In 2007, Excalibur was fielded to U.S. soldiers a year ahead of schedule. As of August 2010, over 500 Excalibur projectiles have been expended in support of Operation Iraqi Freedom and Operation Enduring Freedom with a reliability exceeding the $85 \%$ design threshold.

To increase effective range, Excalibur is undergoing qualification tests for higher charge levels, specifically the U.S. Modular Artillery Charge System (MACS) zone 5. In early testing at Yuma Proving Ground and Fort Sill, the threshold reliability was not achieved with the MACS 5 charge. As a result, several subsystems underwent intensive failure investigation. Once root cause was determined, an engineering redesign was undertaken and production improvements were implemented. The Inertial Measurement Unit (IMU), an electronics package containing microelectro-mechanical systems [15], required manufacturing changes to increase reliability.

\footnotetext{
${ }^{*}$ Corresponding author: J.A. Cordes, U.S. Army ARDEC, Fuze and Precision Armaments Technology (RDAR-MEF-E), Picatinny Arsenal, NJ 07806-5000, USA. E-mail: jennifer.a.cordes.civ@mail.mil.
} 


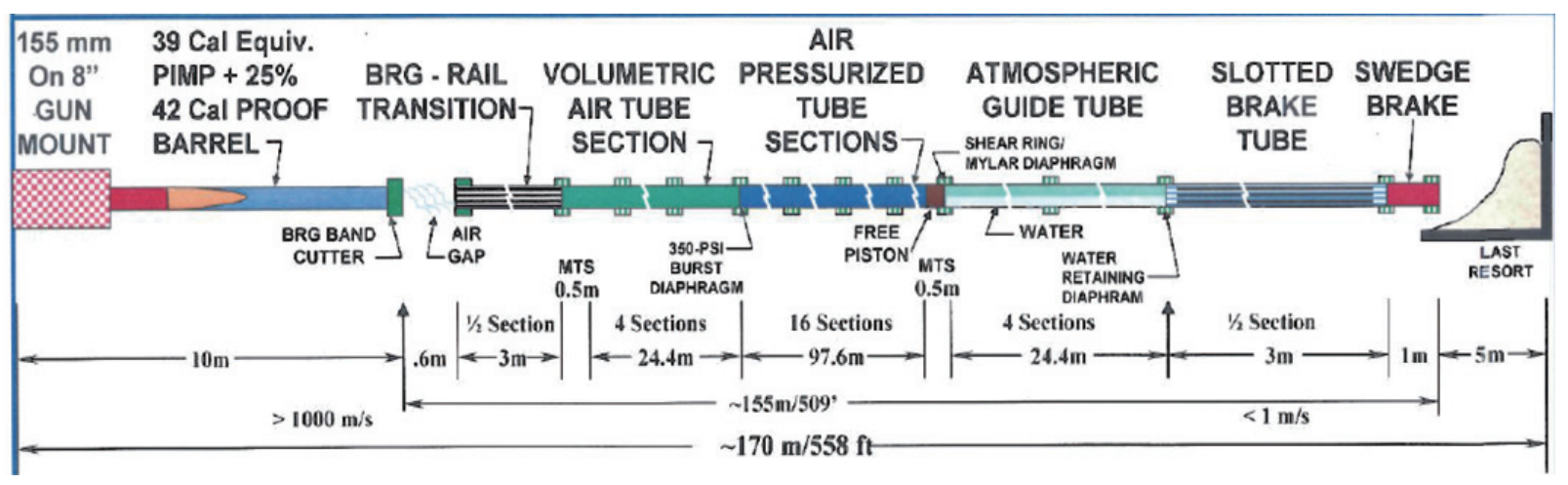

Fig. 1. Soft Catch Gun system, Picatinny Arsenal.

Prior to reliability testing of all-up rounds, the reliability of each IMU production lot is validated by using the Soft Catch Gun facility at Picatinny Arsenal. These tests constitute the IMU LAT. Testing in the Soft Catch Gun is roughly 1/12 the cost of testing tactical rounds at Yuma Proving Grounds. The Soft Catch Gun, Fig. 1, consists of a tactical $155 \mathrm{~mm}$ gun tube and a contiguous series of catch tubes designed to bring the projectile to a stop without damage. Although the muzzle exit accelerations are higher with the Soft Catch Gun, failures, when they occur, are similar to those observed in tactical tests [1]. The failure rates are higher using the Soft Catch Gun which provides additional margin data and even some cost savings. Instead of requiring 100 tactical rounds to prove reliability and function, failures can be detected in 5-10 shots.

The purpose of this paper is to provide data and justification for a reasonable, cost-effective and technically sound strategy for conducting and scoring Excalibur IMU lot acceptance testing. LAT tests would be scored and accepted or rejected based on the SRS, Mil Specification 1540C [16], and a NASA Technical Handbook [17]. According to Section 3.2.2 of MIL-STD-1540C regarding shock environments:

"The level of the maximum expected environment, used for acceptance testing, is that not exceeded on at least 95 percent of flights, estimated with 50-percent confidence (P95/50 level)"

This criterion requires that $95 \%$ of the maximum accelerations fall below the NTL with a $50 \%$ statistical confidence level. Maximum accelerations are determined from the SRS at specific frequencies. The SRS is determined from recorded acceleration versus time data for each gun shot. Axial and transverse accelerations are monitored separately.

The issues are: 1) successful LAT for the IMU reduces the risk of all-up Excalibur rounds not meeting reliability requirements at MACS 5 charges, 2) the Soft Catch Gun is significantly less expensive than tactical firings for testing of the Excalibur IMU and provides additional data products that are highly desirable, 3) the Soft Catch Gun is not an exact match to tactical firings due to the catch event dynamics, 4) excessive over-tests should not be counted as LAT results for IMU production lots, and 5) codified scoring criteria for accepting or rejecting Soft Catch Gun test results do not exist.

This paper presents the 95/50 NTL's for several U.S. gun charges. The 95/50 NTL provides a way to graphically represent and compare data from series' of gun shots. Plots of the SRS for near-tactical firings with MACS 5 charges and for Soft Catch Gun tests with MACS 3, 4, and 5 charges are compared. Near-tactical shots use a higher percentage of the tactical components in an Excalibur projectile than the carrier system normally used for Soft Catch Gun testing. In place of a live warhead, the near-tactical unit has a parachute in the warhead section for a soft landing. After comparing the 95/50 NTL's, a test-acceptance strategy will be chosen and proposed to the Army customer.

The paper also tries to answer the question: in an energetic environment like this is shock spectra analysis the correct tool to use? The Picatinny brake system, considering its cost effectiveness, provides a "near enough" solution. The gun environment is highly-non linear, variable, and of short duration. This is true shock environment. The authors recognize several deficiencies in the SRS method for this application, as outlined in the Discussion Section. For comparison purposes, however, this appears to be a reasonable approach. 
Table 1

Soft Catch Gun system, Picatinny Arsenal

\begin{tabular}{lccc}
\hline \multicolumn{1}{c}{ Test } & $\begin{array}{c}\text { 'Setback' } \\
\text { axial acceleration, } \\
\text { maximum KGs }\end{array}$ & $\begin{array}{c}\text { Transverse } \\
\text { acceleration, } \\
\text { maximum KGs }\end{array}$ & $\begin{array}{c}\text { 'Set forward' } \\
\text { acceleration, } \\
\text { maximum KGs }\end{array}$ \\
\hline $\begin{array}{l}\text { Soft recovery } \\
\text { vehicle and } \\
\text { tactical gun, Yuma } \\
\text { proving ground }\end{array}$ & $14.4(2.03)$ & $4.4(1.66)$ & $-4.9(3.61)$ \\
$\begin{array}{l}\text { Soft Catch Gun, } \\
\text { Picatinny Arsenal }\end{array}$ & $13.1(1.32)$ & $14.6(2.88)$ & $-14.8(5.01)$ \\
\hline \multicolumn{4}{c}{ Averages (standard deviation) } \\
\hline
\end{tabular}

\section{Method}

\subsection{Method, on-board recorders}

Acceleration and pressure data are recorded using on-board recorders. Reference [1] describes the details of the on-board recorders primarily used with the Soft Catch Gun. The location of the on-board recorder is near the IMU's tactical location, Fig. 2.

Data collection in the near-tactical configuration can be summarized as:

- 8 Bit Analog-to-Digital-Converter system

- $500 \mathrm{KHz}$ sampling rate

- $50 \mathrm{KHz}$ bandwidth, Low Pass Filter (6 pole Bessel Filter)

- Around $150 \mathrm{G}$ 's resolution per data point

- 0.350 seconds recording time at $500 \mathrm{KHz}$ sampling rate

Data collection for the Soft Catch Gun configuration was described in detail in [1] and can be summarized as:

- 12 Bit Analog-to-Digital-Converter system

- $1 \mathrm{MHz}$ sampling rate

- $100 \mathrm{KHz}$ bandwidth, Low Pass Filter (8 pole Bessel filter)

- Around 9 G's resolution per data point

- 4 seconds recording time at $1 \mathrm{MHz}$ sampling rate

The Soft Catch Gun data was collected at a higher sampling rate and with a different low-pass filter. For comparison of SRS, the Soft Catch Gun data was downloaded and filtered to be consistent with the data collection on near-tactical test projectiles.

The 8 bit A/D converter used earlier to capture near-tactical data has poor resolution (150 g's) compared to the 12 bit A/D converter (9 g's) used recently to capture the Soft Catch Gun data. By comparing resolution error of these two A/D systems, a lowest transverse acceleration of 4,400 g's measured for a tactical gun in Yuma, shown in Table 1, is used. A one least-significant-bit (LSB) of the 8 bit system at this transverse acceleration represents an error of $3.4 \%(150 \mathrm{~g} / 4400 \mathrm{~g})$ as compare to a $0.2 \%$ error $(9 \mathrm{~g} / 4400 \mathrm{~g})$ for the 12 bit system. As the measured acceleration increases the resolution error decreases. For instance, the resolution error of the 8 bit system lowers to $1 \%$ for a setback acceleration measured at 14,400 g's for the same gun. Despite the 8 bit A/D system has poor resolution (150 g's), it is still an order of magnitude smaller than the acceleration measured for both near-tactical and Soft Catch guns. Therefore, it is justified the resolution error is not overshadowing the data present here. All new instrumented tests at Yuma would use the latest equipment.

Figure 3 shows a typical plot of the acceleration data from the Soft Catch Gun. The curve shows three orthogonal accelerations: axial in the direction of motion through the gun tube and two transverse or balloting accelerations. Setback occurs around $0.004 \mathrm{sec}$ and reaches an acceleration of about $13000 \mathrm{~g}$ 's. Set forward occurs during muzzle exit at about 0.0125 second. In the Soft Catch Gun case there are additional set forward and balloting forces that 


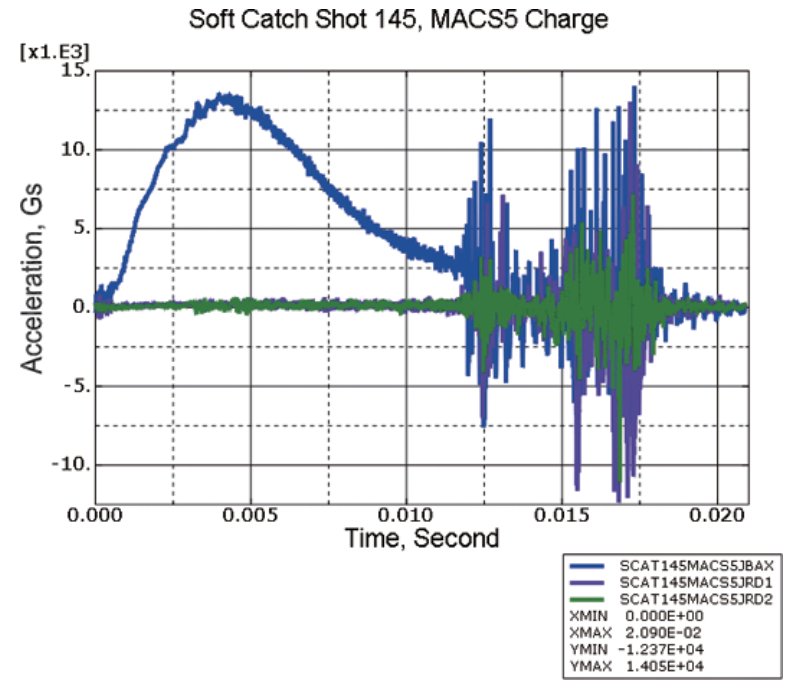

Fig. 3. Acceleration data from a Soft Catch Gun shot (\#145).

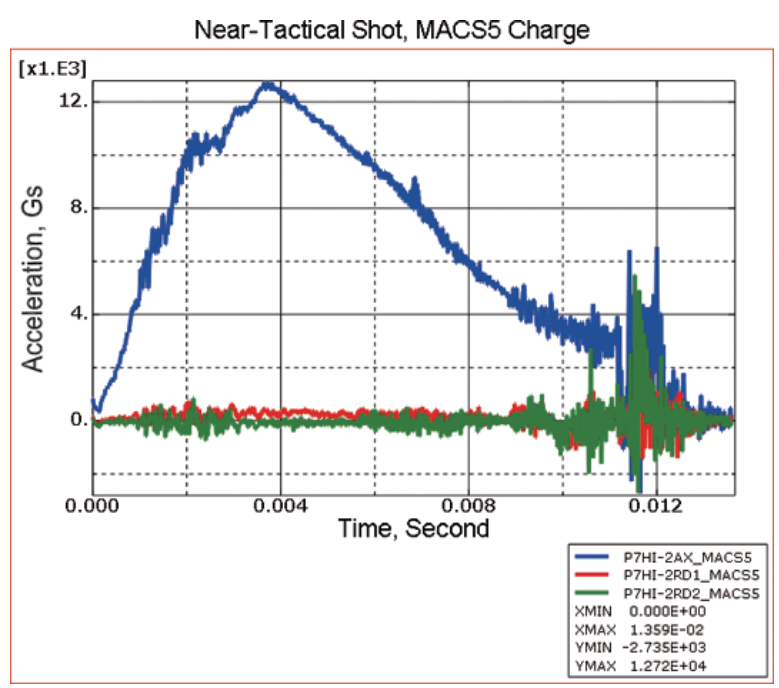

Fig. 4. Acceleration data from a Near-Tactical shot, U.S. MACS 5 Charge.

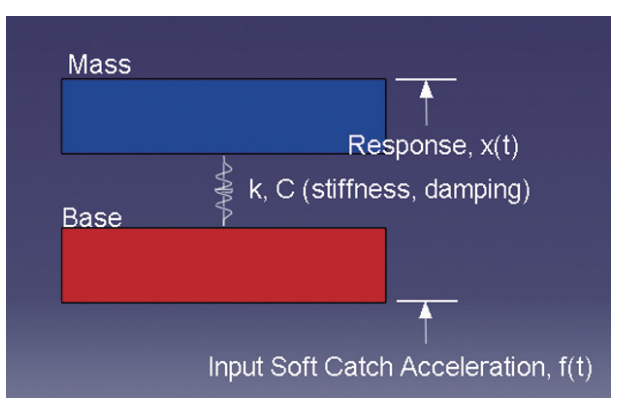

Fig. 5. Simple spring-mass system for shock response.
Shock Response Spectrum, Soft Catch Shot 145, MACS5 Charge

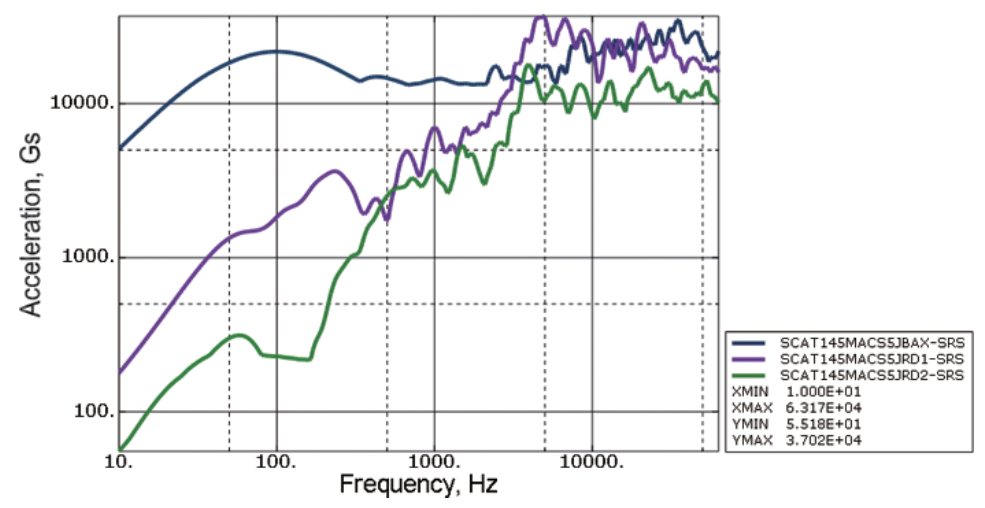

Fig. 6. Shock response spectrum for shot $\# 145, Q=10$. (Note: the blue curve is the axial data and the purple and green curves are transverse data).

occur as the projectile enters the catch tube, at about 0.017 seconds. These additional forces are of higher magnitude than the muzzle exit event. Figure 4 shows a near-tactical shot for comparison. Accelerations are similar until muzzle exit at about 0.011 seconds. After muzzle exit, the near-tactical projectile is in ballistic free flight and the associated accelerations are significantly lower than those seen with the Soft Catch Gun.

\subsection{Method, Shock Response Spectrum}

A Shock Response Spectrum is a graphical representation of the maximum response of a single degree of freedom system to base motion [18,19]. Figure 5 shows a single degree of freedom system. Acceleration versus time history, such as the axial acceleration versus time history in Figs 3 or 4 , is inserted as base motion, $\mathrm{f}(\mathrm{t})$. The acceleration is approximated as a series of polynomials [18]. The governing equation of motion for a single degree of freedom system is solved recursively and the response of the mass, $x(t)$, is determined. The maximum response for the mass is one point on the shock response curve, corresponding to the natural frequency of the 1-degree-of-freedom system.

The recursive digital filters method [19] was used to generate the points in the SRS plots for this paper. Reference [19] also includes the computer algorithm employed for the analysis. Damping was assumed to be 5\%. Figure 6 shows the SRS corresponding to the acceleration time history in Fig. 3. 
In order to validate the accuracy of the SRS algorithm, finite element analyses were performed to determine the peak accelerations for spring-mass systems with different natural frequencies. The finite element analyses provided results for the peak accelerations which closely match the results from the SRS algorithm. For the case study, SRS points agreed to within $2.5 \%$. This SRS data is the source used to determine the NTL.

\subsection{Method, $95 / 50$ Normal Tolerance Limit}

The 95/50 Normal Tolerance Limit represents a technically sound method of establishing an upper limit for the Soft Catch Tests. Establishing the 95/50 Normal Tolerance Limit requires the following steps:

1. Acceleration-versus-time history is recorded using an on-board recorder during a gun shot

2. The acceleration-versus-time history is converted to its associated SRS using the SRS algorithm in [19]. The SRS algorithm provided maximum acceleration responses, $\max \left(x_{i}\right)$ in Fig. 5 , for the same 308 frequencies.

3. For each of the 308 frequencies, the average ( $y_{\text {ave }}$ ) and standard deviations $\left(s_{y}\right)$ are calculated.

4. For each frequency, the 95/50 NTL is found from the statistical average of the log of acceleration ( $y_{\text {ave }}$ ), standard deviation $\left(s_{y}\right)$, and Normal Tolerance Factor $(k)$ at the $95 / 50$ value $[16,17]$. The NTL was calculated for all 308 frequencies:

$$
\begin{aligned}
& N T L(\text { frequency })=y_{\text {ave }}+k^{*} s_{y} \\
& y_{i}=\log _{10}\left(\max \left\{x_{i}(t)\right\}\right) \\
& y_{\text {ave }}=\frac{1}{n} \sum_{1}^{n} y_{i} \\
& s_{y}=\sqrt{\frac{1}{n-1} \sum_{i=1}^{n}\left(y_{i}-y_{\text {ave }}\right)^{2}}
\end{aligned}
$$

For the $n=9$ near-tactical shots at MACS 5, the 95/50 NTL was 1.71; for the $n=10$ soft catch shots at MACS 5, the 95/50 Normal Tolerance Factor was 1.7.

\section{Results}

\subsection{Comparison of maximum accelerations, from recorded time history}

Table 1 contains updated statistical comparisons between MACS 5 charge data for the Soft Catch Gun and data gathered during near-tactical round testing at Yuma Proving Ground [1]. This data was determined from the asrecorded, acceleration versus time history. Table 1 compares the maximum accelerations for 18 Soft Recovery Vehicle (SRV) shots at Yuma and 10 Soft Catch Shots conducted at the Soft Catch Gun Facility. Table 1 indicates that maximum Setback accelerations with the Soft Catch Gun are slightly less than for near-tactical firings at Yuma Proving Grounds.

The two muzzle exit accelerations, set forward and transverse, are higher in the Soft Catch Gun due to impact and interaction with the entrant portion of the catch tube. High-amplitude, muzzle exit accelerations are a known root cause for failures in precision munitions electronic subsystems $[19,20]$. These muzzle exit accelerations represent risk for the current lot acceptance program.

\subsection{Shock response spectrum, Soft Catch Gun}

Figures 7 and 8 illustrate the shock response spectra for several Soft Catch Gun shots at MACS 5 charge level. In Fig. 7, the setback accelerations are displayed at approximately $100 \mathrm{~Hz}$. The higher frequency amplitudes result from set forward accelerations. In Fig. 8, the high frequency, transverse accelerations also occur at muzzle exit. As shown in the Figs 7 and 8, there is significant variation in the shock response spectra. The dark pink line in Fig. 7 and the dark red line in Fig. 8 delineate the 95/50 NTL. Accelerations at some of the frequencies are above the NTL. 


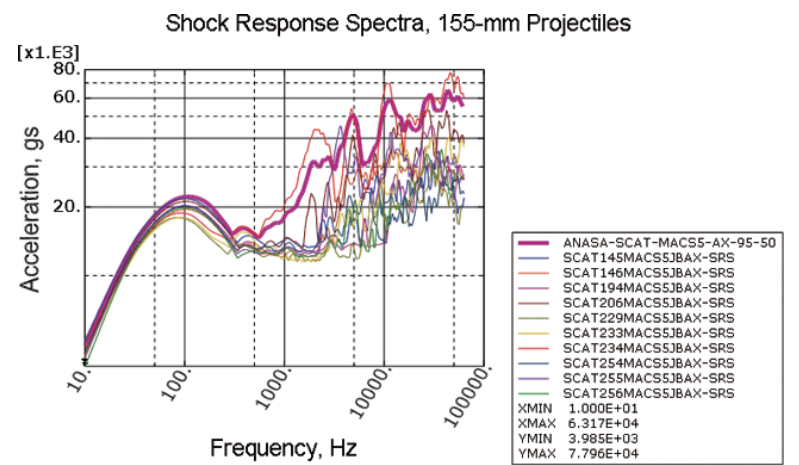

Fig. 7. Shock response, 10 Soft Catch Shots MACS 5, Axial, $Q=10$

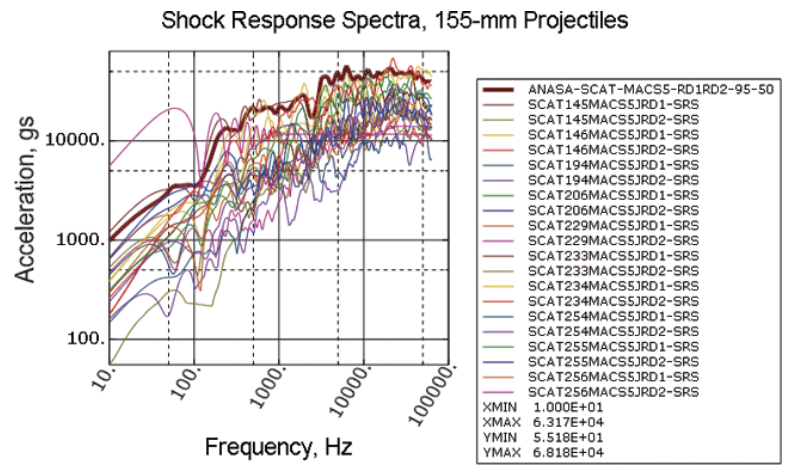

Fig. 8. Shock response, 10 Soft Catch Shots MACS 5, transverse, Q = 10 .

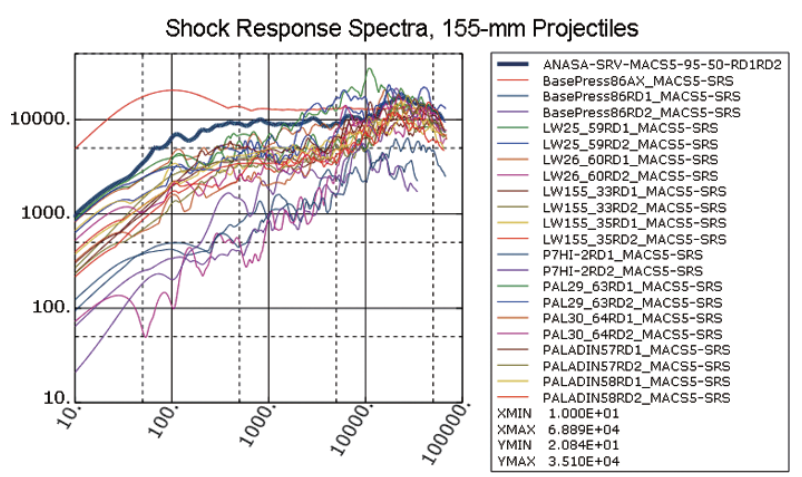

Fig. 10. Shock response spectrum for 9 near-tactical shots, transverse, $\mathrm{Q}=10$.
Fig. 9. Shock response spectrum for 9 near-tactical shots, axial, $\mathrm{Q}=10$.

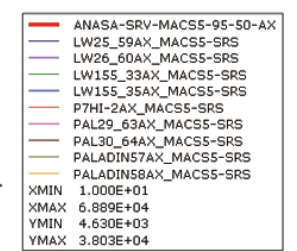

\subsection{Shock response spectra, near-tactical shots}

Figures 9 and 10 illustrate the shock response spectra for nine near-tactical shots at Yuma Proving Grounds. Figure 9 shows a comparison of axial accelerations and Fig. 10 shows a comparison of transverse accelerations. The Yuma shots were completed with the Soft Recovery Vehicle (SRV). The SRV has a parachute section that replaces the Excalibur warhead. The parachute is deployed when the projectile reaches apogee. Any failures are attributed to the in-barrel or flight environment as the parachute deploy event and subsequent ground impact are relatively benign. Shots were completed with the Paladin and Joint Light Weight 155 gun tubes. As shown in the Figs 9 and 10, there is significant variation in the SRS. The dark red line in Fig. 9 and the dark green line in Fig. 10 show the 95/50 NTL.

Figures 11 and 12 compare the 95/50 NTL's between the two test systems. Results are consistent with Table 1. Setback accelerations, at about $100 \mathrm{~Hz}$ are higher in the near-tactical test events. The higher frequency accelerations are higher in the Soft Catch Gun due to the previously identified impact and interaction dynamics with the entrant portion of the catch tube.

Figures 13 and 14 illustrate the 95/50 NTL for the near-tactical MACS 5 charge and several different chares for the Soft Catch Gun. The breech pressure for a MACS 3 charge at ambient temperature is approximately $130 \mathrm{MPa}$, MACS 4 charge is approximately $212 \mathrm{MPa}$ and MACS 5 charge is approximately $332 \mathrm{MPa}$. The SRS were computed for thirteen MACS 3 charges and for six MACS 4 in the Soft Catch Gun. At some of the higher frequencies, the MACS 3 and MACS 4 accelerations are closer to the near-tactical MACS 5 charge. As shown in the Figs 13 and 14, there is a cross over in the 95/50 NTL's.

Tables 2 and 3 present additional comparisons between the 95/50 NTL's for the Soft Catch Gun and the neartactical shots in the axial direction. Table 3 shows the calculated SRS accelerations at key frequencies; Table 4 


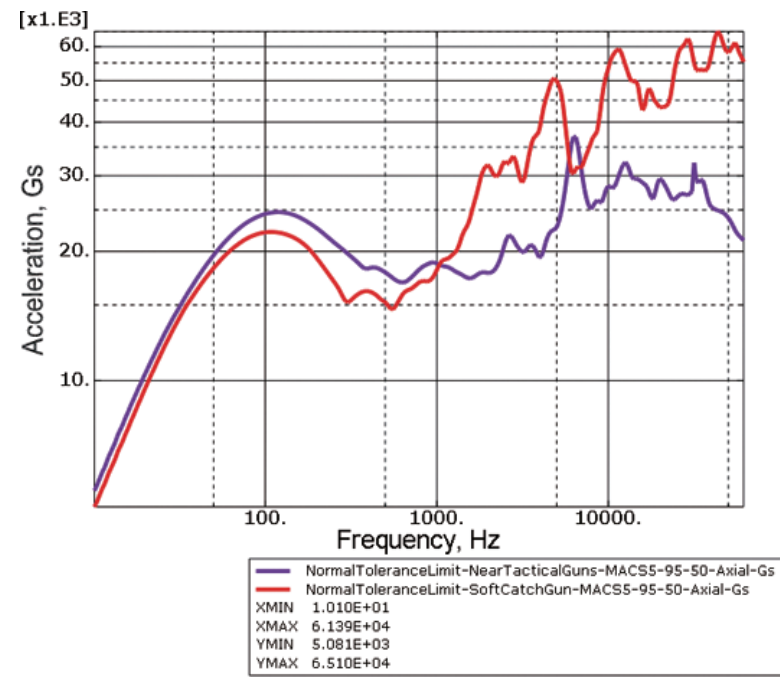

Fig. 11. Comparison of normal tolerance limits, macs 5 charge, axial direction, $\mathrm{Q}=10$. (Purple curve is for the near-tactical shots; Red curve is from the Soft Catch Gun).

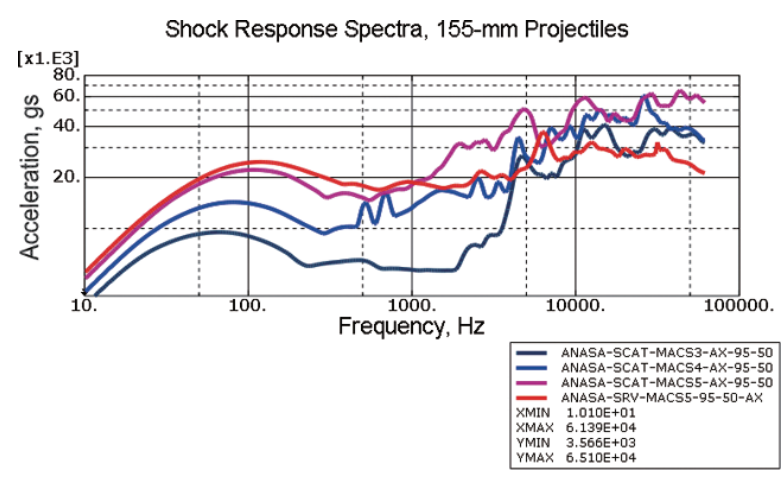

Fig. 13. Comparison of normal tolerance limits, MACS 3, 4 and 5; axial, $Q=10$. (Note: The red curve is the SRS for the near-tactical MACS 5 shots).

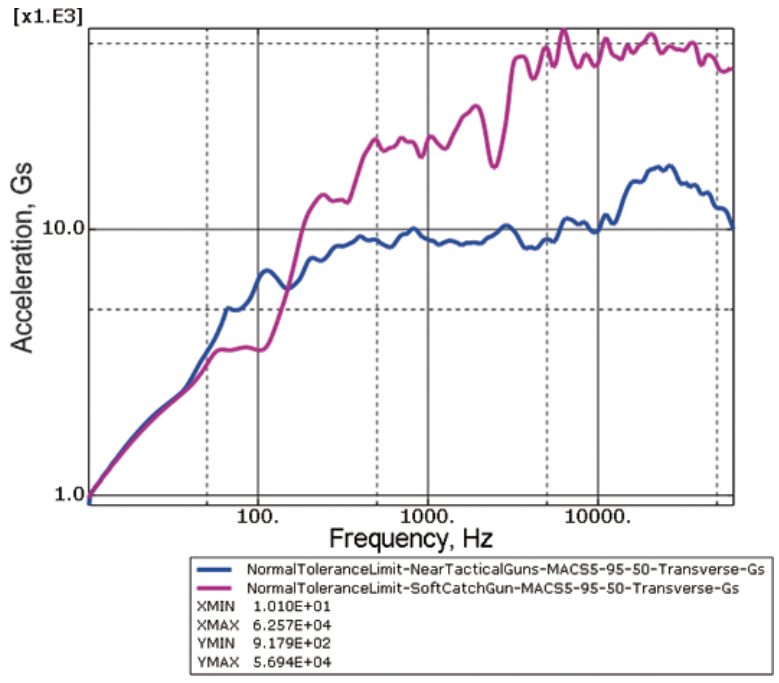

Fig. 12. Comparison of normal tolerance limits, MACS 5 charge, transverse, $Q=10$. (Pink curve is for the Soft Catch Gun; Blue curve is for the near-tactical shots)

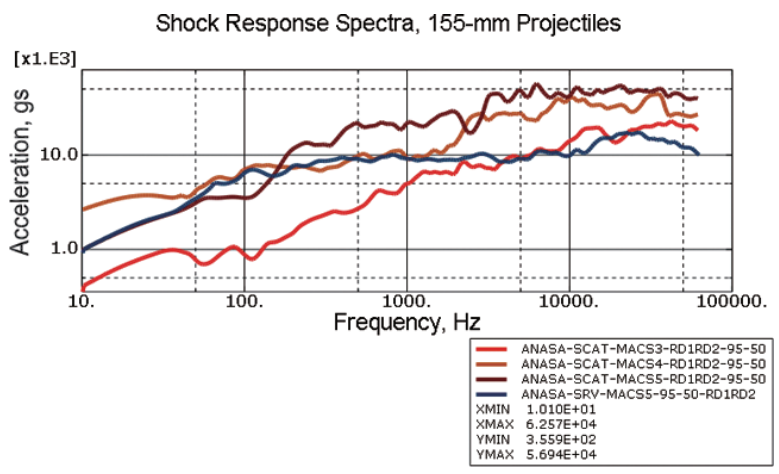

Fig. 14. Comparison of normal tolerance limits, MACS 3, 4 and 5; transverse, $\mathrm{Q}=10$. (The blue curve is the SRS for the near-tactical MACS 5 shots).

shows differences at specific frequencies. The $117 \mathrm{~Hz}$ frequency is around setback. Setback is higher for the near tactical shots. The $4307 \mathrm{~Hz}$ and $28970 \mathrm{~Hz}$ accelerations occurred at or after muzzle exit. The delta between the near-tactical MACS 5 charge and the Soft Catch Gun, MACS 4 charge is less than $6 \mathrm{~dB}$. Based on experience and history, frequency differences greater than $6 \mathrm{~dB}$ are considered significant [16].

Tables 4 and 5 show similar results for the transverse 95/50 NTL's. Again, at higher frequencies, the accelerations from the 95/50 NTL are higher for the Soft Catch Gun.

\section{Discussion}

The 95/50 NTL's provide a graphical summary for a series of acceleration histories. It is based on the SRS for individual gun shots. The SRS curves are regularly used to assess damage potential of earthquakes and pyrotechnic shocks [17]. It is not clear that 95/50 NTL's using SRS comparisons are appropriate for assessing the damage potential for electronics experiencing gun launch dynamics. 
Table 2

Comparison of 95/50 normal tolerance limits, axial acceleration

\begin{tabular}{lcccc}
\hline \multicolumn{4}{l}{ Comparison of axial limit accelerations, gs, at different } & frequencies \\
\hline Frequency & SRV & SCG & SCG & SCG \\
Hz & MACS 5 & MACS 5 & MACS 4 & MACS 3 \\
\hline 117 & 24696 & 22157 & 13722 & 8611 \\
4307 & 20984 & 45148 & 31383 & 22305 \\
28970 & 27049 & 62576 & 48503 & 37788 \\
\hline
\end{tabular}

SRV: Soft recovery vehicle, near-tactical shots, Yuma proving ground SCG: Soft catch gun, Picatinny Arsenal

Table 4

Comparison of 95/50 normal tolerance limits, transverse accelerations $\overline{\text { Comparison of transverse limit accelerations, Gs, different frequencies }}$

\begin{tabular}{lcccc}
\hline Frequency & SRV & SCD & SCD & SCD \\
Hz & MACS 5 & MACS 5 & MACS 4 & MACS 3 \\
\hline 117 & 6984 & 3774 & 7774 & 815 \\
4306 & 8458 & 37670 & 26895 & 9520 \\
28968 & 15951 & 47290 & 38574 & 20026 \\
\hline
\end{tabular}

Table 3

Difference in dB's between shot series, axial accelerations

\begin{tabular}{lccc}
\hline \multicolumn{4}{c}{$\begin{array}{c}\text { Delta dB: Near-tactical (SRV) and Soft Catch Data (SCD), } \\
\text { Axial }\end{array}$} \\
\hline Frequency & $\Delta \mathrm{dB}$ & $\Delta \mathrm{dB}$ & $\Delta \mathrm{dB}$ \\
$\mathrm{Hz}$ & SRV MACS 5 \& & SRV MACS 5 \& & SRV MACS 5 \& \\
& SCD-MACS 5 & SCD-MACS 4 & SCD-MACS 3 \\
\hline 117 & -0.9 & -5.1 & 9.2 \\
4307 & 6.7 & 3.5 & -0.5 \\
28970 & 7.3 & 5.1 & -2.9 \\
\cline { 2 - 4 } & \multicolumn{3}{c}{$\Delta \mathrm{dB}=20 * \log 10(a / b)[16]$} \\
\hline
\end{tabular}

Table 5

Difference in dB's between different data sets, transverse

\begin{tabular}{lccc}
\hline & \multicolumn{3}{c}{ Delta dB: Near-tactical and Soft Catch Data, Axial } \\
\hline Frequency & $\Delta \mathrm{dB}$ & $\Delta \mathrm{dB}$ & $\Delta \mathrm{dB}$ \\
$\mathrm{Hz}$ & SRV MACS 5 \& & SRV MACS 5 \& & SRV MACS 5 \& \\
& SCD-MACS 5 & SCD-MACS 4 & SCD-MACS 3 \\
\hline 117 & -5.3 & 0.9 & -18.7 \\
4307 & 13.0 & 10.0 & 1.0 \\
28970 & 9.4 & 7.7 & 2.0 \\
\hline
\end{tabular}

\subsection{Assumptions for lognormal distribution}

The 95/50 NTL is based on the assumption of a lognormal distribution of the acceleration points at a given frequency [15]. This assumption was checked for several key frequencies. None of the frequencies had a best-fit to lognormal distribution. For instance, for the near tactical shots at a frequency of $4300 \mathrm{~Hz}$, the data points had a 0.2/1.0 fit to a lognormal distribution. Rayleigh distribution had a fit of 0.7./1.0 at $4305 \mathrm{~Hz}$. The goodness of fit is between zero and one, one indicating an exact statistical distribution. The software package DistributionProbe [22] was used to determine the best-fit statistical function to represent the average, maximum, accelerations. DistributionProbe includes 15 statistical distributions and three goodness-of-fit tests. The Anderson-Darling goodness of fit test was used for the data points.

\subsection{Multi-directional forces}

Numerous transient dynamic analyses have been completed on electronics subjected to gun launch dynamics, for instance [8,9,12-14,20]. The combined effect of axial and balloting accelerations presents a constantly changing force vector affecting survivability of solder joints, solid state devices, circuit cards and supporting structures. The shape of the circuit board under load is not the usual membrane shape unless balloting forces are zero. The detailed analysis of micro-electro-mechanical systems in previous studies indicated that damage occurred when balloting forces were relatively large [12]. As indicated in Figs 3 and 4, large balloting forces are usually coupled to large set forward forces at muzzle exit and beyond. This coupling is due to muzzle exit impact arising from balloting, yawing and tip-off of the projectile combined with entrance and transit of the catch tube system. This 3-dimensional failure mode is not accounted for in the single degree of freedom SRS approximation.

\subsection{Non-linearity}

The SRS governing equations are based on natural frequency, a linear assumption. Precision munitions, such as Excalibur, are not linear systems. Joints, contact, and yielding preclude linear behavior [8-13,19]. Although modal superposition is sometimes used for a quick estimate of at-risk components, it is generally not used as a design tool at Picatinny Arsenal due to nonlinear effects. 


\subsection{Multi-degree of freedom system}

Transient dynamic analysis of electronics packages requires modeling of chips, solder, boards, and supporting structures $[8,9,13]$. Finite element models usually have greater than a million degrees of freedom. The SRS approximation is completed with a single-degree-of-freedom system. The effect of multiple degrees of freedom is not considered in the SRS or the 95/50 NTL's.

\subsection{Shape of the shock wave}

Actual shock response is a function of the type of shock wave: half-sine, saw-tooth, pyrotechnic etc. The shape of the shock wave is not reflected in the SRS calculations.

\subsection{Transmission of base motion}

The IMU has some damping around the outer housing. The attenuation effect of the housing is not included in the SRS approximations. The inside of the current IMU is potted. The stiffness and damping characteristics of the potting, and associated change over temperature [23], are not included in the SRS approximation.

\subsection{Location, location, location}

The SRS is a function of a specific subsystems location within the projectile. Mechanical joints, distance from the center of mass, and local closures affect the SRS.

\subsection{Carrier differences}

There are significant mechanical differences between the projectile primarily used in the soft catch tests and the near-tactical unit. The carrier in the Soft Catch Gun includes multiple locations for the Inertial IMU's to save on test costs.

It should be noted that the near-tactical carrier, called the SRV, is not equivalent to the tactical carrier. The two rounds are different in several ways. The SRV carrier was initially intended to survive Permissible Maximum Pressure $(\mathrm{PMP})+25 \%$. The warhead section is modified to contain the parachute and expulsion system and to withstand the PMP $+25 \%$ load. The tactile round was designed to survive PMP $+5 \%$.

The SRV had several different functions relative to the tactical round. Unlike the tactical carrier, the SRV was designed to carry an OBR (On-Board-Recorder), a different Fuze Safe and Arm (FSA), and a Guidance Navigation Control (GNC) section. Here are some excerpts from the document describing the near-tactical SRV carrier [24]:

"The weight and cg were designed to be nearly identical to a tactical round; Weight: $+/-0.3 \mathrm{lb}$, Center of Gravity: +/-10 mm and Pitch, Yaw, Roll Moments of Inertia: +/-10\%. The structural stiffness had to be within $10 \%$ of tactical. The joints had to be tactically located for the base and GNU

The cargo area had to accommodate either an OBR, a tactical FSA or an ARRT-113, the cargo area was located in the upper portion of what would be the tactical payload section. The other part of the cargo area housed the parachute and ERC (timer) systems. There are non-tactical joints created by the separate sections of the SRV mid-body."

The dynamic response was never compared (or at least not documented). Neither the Army nor Raytheon ever went so far as to compare the response of SRV to a tactical round. Therefore the dynamic similarity between the two rounds is currently unknown.

\subsection{Low-cycle fatigue}

Some transient analyses indicate plasticity occurs during Setback. As the projectile continues through the gun barrel, yielded parts are subjected to multiple impacts in reversing directions. These impacts sometimes cause low- 
cycle fatigue which is not included in the SRS assumptions. If one compares the number of impacts in the Rail Gun (a system similar to the Soft Catch Gun), the Soft Catch Gun, and the near-tactical configuration, one sees many more impacts for the Picatinny Rail Gun and Soft Catch Gun [1-6]. Sub-systems that repeatedly survive the Picatinny Rail Fun nearly always have high reliability in the tactical configurations. Fatigue effects are not included in the SRS calculations and may represent a better LAT criteria. This may be investigated at a later date.

\subsection{Acceptance criteria for tests}

Despite some questionable assumptions for using the 95/50 NTL's for gun-launched electronics, the method provides metrics to represent and assess a series of gun test events. Results are fairly consistent with simple acceleration maxima, Table 1. Use of the maximum balloting force, with its actual statistical distribution, might provide an easier assessment of which shots are statistically outside normal values. Future work might focus on investigating which parameters correlate best to the reliability of gun-shocked electronics.

\section{Conclusion}

The Army understands that the Soft Catch Gun environment is not the same as the tactical environmental experienced by the Excalibur projectile. The Army also understands that the near-tactical carrier is not the same as the tactical carrier. For these reasons, testing in the Soft Catch Gun is not completely representative of the tactical weapon stimulus. Similarly, testing with the near-tactical configuration is not the same as a tactical firing or test event.

The basic problem is summarized thusly: Lot acceptance tests in a tactical weapon are relatively expensive. At the same time, lot acceptance tests in the Soft Catch Gun, while less expensive, significantly increase risk of unnecessary LAT failures owing to over-test. The soft catch tests provide a close approximation of the setback and in-bore balloting loads for the tactical Excalibur launch event. The muzzle exit dynamics seen in the Soft Catch Gun are significantly more severe than are acceptable for carte blanch scoring. In addition, the frequency content at muzzle exit differs significantly between the Soft Catch Gun and the near-tactical firings.

For many of the reasons given in the discussion section, the Army does not currently support the proposed 95/50 criteria for acceptance of the LAT results. The Army does not object to Raytheon's use of the tests to mitigate their own risk. The 95/50 NTL's for the muzzle exit accelerations have been proposed by Raytheon for Lot Acceptance Tests of electronics packages for Excalibur. LAT, in this case, is intended for risk mitigation and is not a requirement for all sub-systems. It is proposed that an acceptable environmental stimulus envelope be established around the 95/50 NTL criteria and that soft catch test data that falls within that envelope should be accepted for scoring as LAT results and those data falling outside the envelope be retained as useful engineering margin information but rejected for the purposes of LAT scoring. It is believed that by conducting soft catch testing in this way, the maximum value will be achieved for all parties. Elimination of some soft catch test results from the LAT score will increase the cost of testing as $25 \%$ of all data analyzed for this paper would have been rejected by this method but this is relatively trivial compared with conducting the same testing using tactical or near-tactical configurations. This approach also allows system margin data to be gathered and analyzed on those test events with super-tactical acceleration magnitudes and frequency content, further contributing to the understanding and reliability of this important weapon system.

\section{Acknowledgments}

The authors would like to thank the Excalibur team for maintaining excellent records regarding reliability. A special thanks to S. Hromnak for providing reliability from the Iraq and Afghanistan wars. The authors also wish to thank the crew of the Soft Catch Gun at Picatinny Arsenal, lead by Nigel Gray and Greg Hader.

\section{References}

[1] J.A. Cordes, J. Lee, G. Hader, L. Reinhardt, C. Kessler, N. Gray and M.A. Guevara, Statistical comparisons between qualification tests for gun-fired projectiles, ASME Journal of Applied Mechanics 77(5) (2010), 051602-1-051602-6. 
[2] J.A. Cordes, J. Lee, T.L. Myers, G. Hader, L. Reinhardt, C. Kessler, N. Gray and M.A. Guevara, Statistical comparisons between qualification tests for gun-fired projectiles, 25th International Symposium on Ballistics, Beijing, China, W. Zhongyuan, Z. Xiaobing and A. Yude, eds, 17-21 May 2010, pp. 594-597.

[3] T. Myers, D. Geissler, B. Ellis, J.A. Cordes and J. Vega, Statistical comparison between component level and system level testing for the excalibur projectile, 23rd Int, Symposium On Ballistics Tarragona, Spain 16-20 April 2007.

[4] T. Myers, D. Carlucci and J. Cordes, Rail gun test projectile for improved developmental testing of precision munition electronics, Proceedings of the 22nd International Symposium on Ballistics, (14-18 November 2005), 427-434.

[5] J. Cordes, J. Vega, D. Carlucci and R. Chaplin, Design accelerations for the army's excalibur projectile, Picatinny Technical Report, ARAET-TR-05008, 2005.

[6] J. Cordes, J. Vega, D.E. Carlucci, R. Chaplin and W.S. Peterson, Structural loading statistics of live gun firings for the army's excalibur projectile, Picatinny Technical Report ARAET-TR-05005, DTIC ADA431877, 2005.

[7] M. Hollis, B. Flyash, A. Bahia, J. Potucek and D. Carlucci, Empirical measurements of cannon launch pressures on a finned 155 mm artillery projectile, 21 ${ }^{\text {st }}$ International Sym, on Ballistics, 19-23 April 2004.

[8] J.A. Cordes, D.E. Carlucci, J. Kalinowski and L. Reinhardt, Design and development of reliability gun-fired structures, Technical Report ARAET-TR -06009, U.S. Army Armament Research Development and Engineering Center, Dover, NJ, (2006).

[9] J. Lee, S. Groeschler, D. Geissler and B. Armstrong, Simulation analysis of impact delay module, Technical Report ARMET-TR-08021, U.S. Army Armament Research Development and Engineering Center, Dover, NJ, (2008).

[10] M.R. Chowdhury, A. Frydman, J. Cordes, L. Reinhardt and D. Carlucci, 3-D finite-element gun launch simulation of a surrogate excalibur 155-mm guided artillery projectile-Modeling capabilities and its implications, Proceedings of the 22nd International Symposium on Ballistics, (14-18 November 2005), 259-267.

[11] J.A. Cordes, D. Carlucci and R. Jafar, Dynamics of a simplified 155-mm projectile, 21 st International Symposium on Ballistics, Adelaide, South Australia, (19-23 April 2004), pp. 1164-1170.

[12] P. Carlucci, J.A. Cordes, N. Payne, L. Reinhardt and D. Troast, Dynamic analysis of electronic components for precision munitions, a case study, Technical Report ARMET-TR-09022, U.S. Army Armament Research, Development and Engineering Center, Picatinny Arsenal, NJ, 2009.

[13] V. Chakka, M.B. Trabia, B. O'Toole, S. Sridharala, S. Ladkany and M. Chowdhury, Modeling and reduction of shocks on electronic components within a projectile, International Journal Of Impact Engineering 35 (2008), 1326-1338.

[14] S. Habibi, S.J. Cooper, J.M. Stauffer and B. Dutoit, Gun hard inertial measurement unit based on MEMS capacitive accelerometer and rate sensor, Position, Location and Navigation Symposium, 2008 IEEE/ION.

[15] Military standard: Test requirements for launch, upper-stage, and space vehicles, ADA286627, MIL-STD-1540C, 1994.

[16] H. Himelblau, J.E. Manning, D.L. Kern, A.G. Piersol and S. Rubin, Dynamic environmental criteria, NASA technical handbook, NASAHDBK-7005, 13 March, 2001, pp. 129-178.

[17] J.N. Martin, A.J. Sinclair and W.A. Foster, On the shock-response-spectrum recursive algorithm of kelly and richman, NASA Center: Marshall Space Flight Center, Document ID: 20100002199; Report Number: M10-0157.

[18] T. Irvine, An introduction to the shock response spectrum, Revision Q, http://www.vibrationdata.com/SRS.htm.

[19] D.E. Carlucci and S.S. Jacobson, Ballistics, Theory and Design of Guns and Ammunition, CRC Press, Boca Raton, FL 22487.

[20] D. Carlucci, J. Cordes, S. Morris and R. Gast, Muzzle exit (set forward) effects on projectile dynamics, Technical Report ARAET-TR06003, U.S. Army Armament Research Development and Engineering Center, Dover, NJ, 2006.

[21] Test operations procedure (TOP) 5-2-521 pyrotechnic shock test procedures, Survivability, Vulnerability and Assessment Directorate (TEDT-WS-SV-A), US Army White Sands Missile Range, 2007.

[22] DistributionProbe, V1.2. PredictionProbe Inc., Irvine, CA, USA, 2006.

[23] N.H. Chao, J.A. Cordes, D. Carlucci, M.E. DeAngelis, S. Marhevka, J. Lee, L. Reinhardt and M. Tesla, The use of potting materials for electronic-package survivability insmart munitions, accepted for presentation in: Proceedings of the 2010 International Mechanical Engineering Conference and Exposition, IMECE10, Vancouver, Canada, IMECE2010-37433, 12-18 November 2010.

[24] General dynamics ordnance and tactical systems, SRMB Requirements, Internal Report, October 2002. 

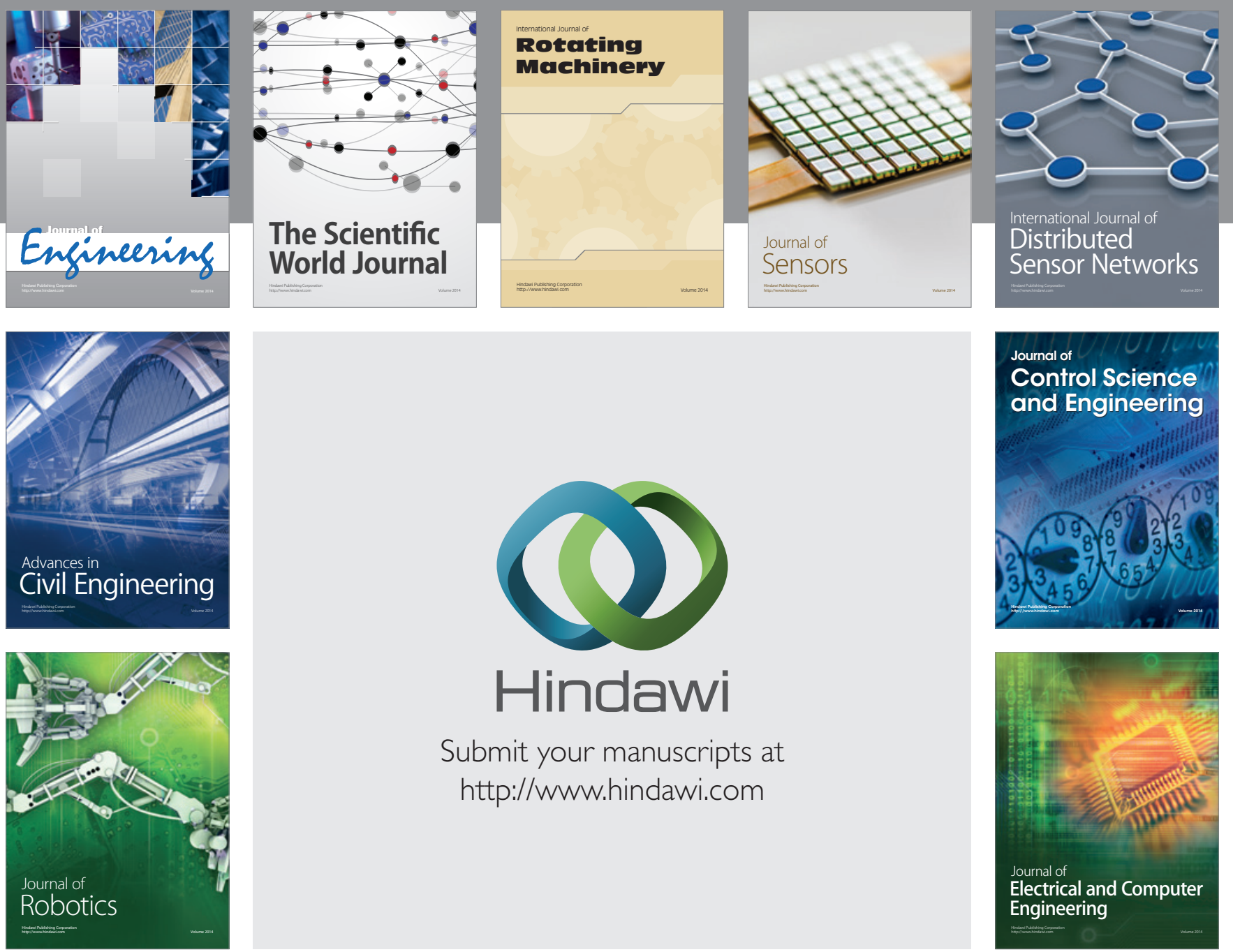

Submit your manuscripts at

http://www.hindawi.com
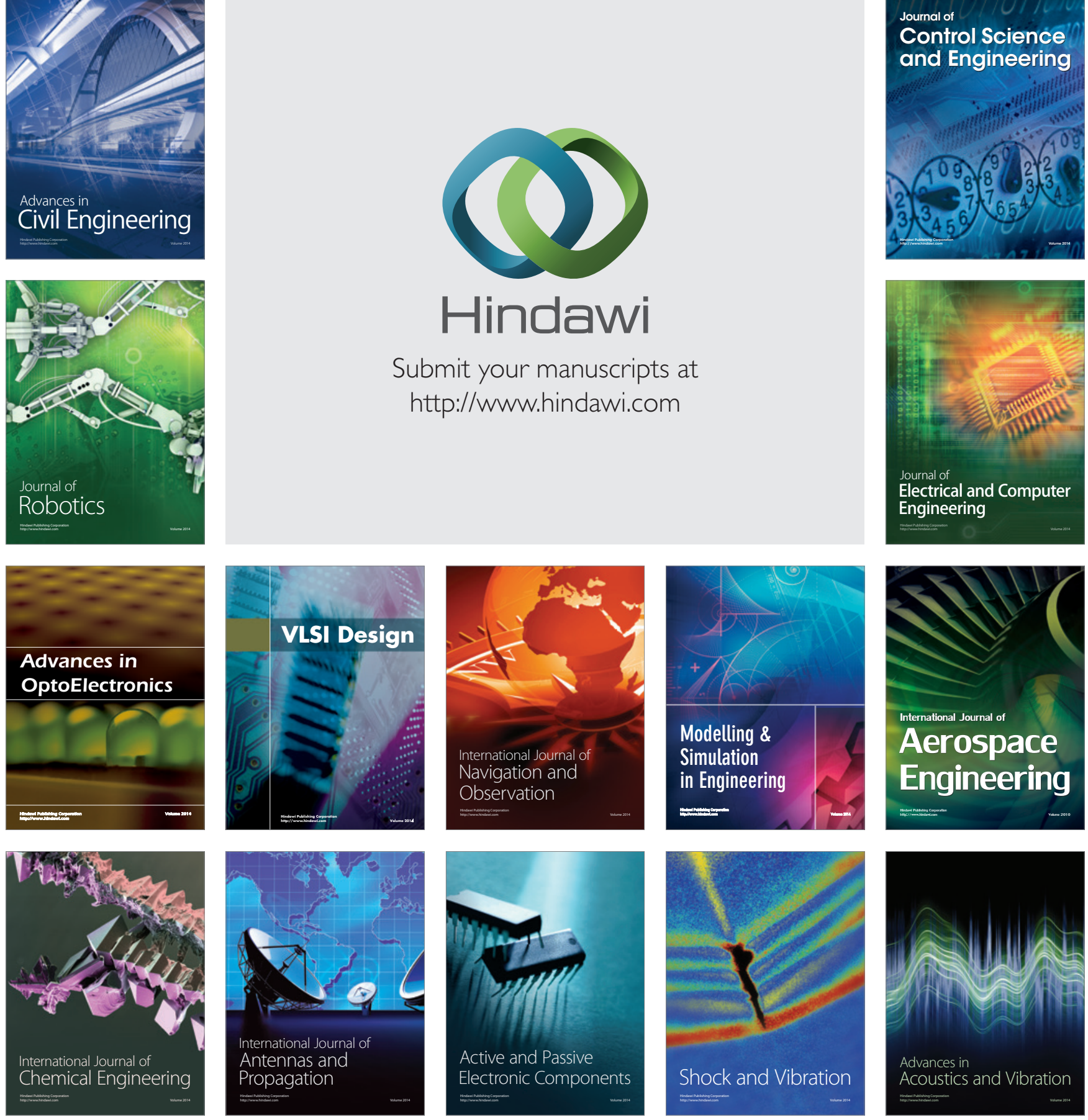